\title{
Study on the Assessment and Reduction of Ergonomics Risks in the Construction Field
}

\author{
Adrian ISPĂSOIU \\ Transilvania University of Brasov, Romania, adrian.ispasoiu@unitbv.ro \\ Ioan MILOSAN \\ Transilvania University of Brasov, Romania, milosan@unitbv.ro \\ Dorin SENCHETRU \\ Territorial Labor Inspectorate of Brasov, Romania, dorin senchetru@yahoo.com \\ Ana Maria Florina ISPĂSOIU \\ Maastricht University, Netherlands, ispasoiuana@yahoo.com
}

\begin{abstract}
At national level it is found that ergonomics at work is not given sufficient importance, such that many employees suffer from musculoskeletal disorders (MSDs). In Romania the insurer, who is also in charge of preventive activities, Ministry of Health through labor medicine, which is in charge of preventive activities as well, and Labor Inspection through Territorial Labor Inspectorates, which have control attributions, did not handle problems regarding ergonomics well enough, such that many disorders of the employees are caused by the fact that ergonomic rules are not respected or taken seriously. The present paper carries out a study on the health and safety of Romanian employees. It mainly considers weight lifting, which is an activity found in all companies, and focuses on assessing ergonomic risks. In this first study, employees working on construction sites in Bucharest, Ilfov County and Brasov County participated. These sites are active for at least 10 months. It was revealed that on most sites ergonomic principles are not considered, but most alarming is that they are not even acknowledged. In this sense, this study aims to identify the ergonomic risks, according to the activities carried out, and then, using QERA method, which was developed within this study, to estimate and assess these risks. Following this assessment, a plan with efficient measures is developed which contains actions for informing, training and raising awareness of the employees and employers regarding ergonomic risks while highlighting the benefits of respecting them. A study prior to applying the measures is made and, after 6 months from the time preventive measures have been implemented, positive results concerning the reduction of ergonomic risks can be observed. This is supported by a reduction in the number of ailments. At the same time, an increase in the productivity and efficiency of workers is observed and it results in a reduction in the number of sick days as well as reduced fluctuations of personnel.
\end{abstract}

\section{Keywords}

ergonomic risk assessment, risks in the construction sector, security, musculoskeletal disorders (MSD)

\section{Introduction}

Safety is defined as the absence of uncontrollable risks and is concerned with values regarding life, health, property, environment, and civil rights and liberties. Safety is one of the most important human needs and should therefore be subjected to special protective measures. The right to safety is an inalienable human right and the government, being a system that organizes social life, should protect it [1].

Workplace safety is influenced by many factors, both technical and organizational, as well as factors concerned with employees' training, including their attitude towards risks, environmental factors etc. [1].

Musculoskeletal disorders (MSDs) remain the most common work-related health problems in the European Union (EU). MSDs concern workers in all sectors and occupations. Besides the effects on workers themselves, they lead to high costs to enterprises and society [2].

In the construction field, where most of the unqualified work activities are carried out, i.e., manual material handling, the highest number of musculoskeletal disorder (MSD) cases are found compared to any other field, at least theoretically. 
The present study identifies some of the activities in the (civil) construction industry that causes the most MSDs to the employees. These activities are either carried out by the employees having a certain duty or by the employees having different duties but that do activities together.

It was revealed that in many situations employees are not aware and/or do not respect the minimal rules for occupational health and safety (e.g. not wearing the appropriate PPE designed for the risks of the activities carried out, having postures that affect their health, use equipment that is improvised or misfit for the work task etc.). These situations have multiple causes, beginning with imposing a short time for completing a task, to not assuring adequate technical means for the work task (e.g. scaffold, platforms, tools etc.) and possibly ending with employer carelessness regarding employees' health and even employee carelessness regarding their own health and safety.

In this study we made questionnaires and interviews for the employees working on different construction sites and observed them perform specific activities, especially those that usually result in health problems and were identified as such by them.

There were 6 construction sites, each having a minimum number of 50 employees. The constructions took minimum 10 months and the sites were in Bucharest, Ilfov County and Brasov County.

Over 100 employees were interviewed, and 54 questionnaires were completed.

The workers that were interviewed had jobs such as blacksmiths, blacksmith-benders, masons, carpenters, pavers, tile installers, scaffolders, electricians, mechanical locksmiths, welders, dry wallers, warehouseman, concrete installers, and unqualified employees.

\section{Materials and Methods}

Ergonomics includes three main areas: physical, cognitive and organizational [3]. The present study considers this.

Awkward postures are body postures when conducting an activity that are significantly altered from the neutral posture. Examples of awkward postures are: twisting, bending, working with hands above the head, sitting on knees, etc. [4].

The important factors causing ergonomic risks are: awkward postures, holding weights away from the body, holding awkward postures for too long [5].

The most important risk factors are the physical ones. These include posture, force, repeated movements, vibrations, combinations of these factors. These result in cumulative damages [6].

The questionnaire consisted of questions chosen in such a way that the employees could answer them quickly and easily. It was comprised of 31 questions that covered 5 interest areas: training (2 questions), material handling (13 questions), tools (3 questions), awkward postures (7 questions), and musculoskeletal disorders (6 questions).

It was possible for the employees to explain their answers in the 'Observations' column, although some questions are closed and require on yes/no, while others are open and require descriptive answers (for example, 'Which tools are heavy and difficult to handle?'). The sample of employees that were questioned represents the target group and the number is statistically significant.

Subsequent to analysing the workers' answers and by direct observation of the activities they carry out, it was revealed that, regardless of the task involved, most of them suffer from lumbar ailments and ailments of the shoulders, arms and knees (for those who require to sit on their knees while working). Nevertheless, the employees did not communicate any of this to the occupational medicine doctors, to the employers or to other specialists in the field (specialist doctors).

Considering these findings, within this study, we have established a simple and quick method specific and useful to both employers and employees- for evaluating the ergonomic risk factors while considering body and limb posture, the tasks involved, exposure time, etc. Following this method, appropriate measures related to performing activities in optimal ergonomic conditions can be taken.

Moreover, it was found that, although some workers state that they have been correctly trained for working adequately, they still do not follow ergonomic principles. There are multiple reasons why workers do not follow them. These include the fact that workers do not realize the importance these principles have on their health and safety and the absence of appropriate technical means that would help workers avoid exposure to ergonomic risks. 


\subsection{Method description of Quick Ergonomic Risks Assessment (QERA)}

The QERA method aims to quickly identify possible musculoskeletal ailments of the employees performing different activities. As a result, if these ailments have the possibility to arise, active measures can be taken to prevent them. On the other hand, if the method is used on ongoing activities, reactive measures can ameliorate possible ailments.

In order to apply QERA method it is not required to have in-depth knowledge of occupational health and safety. Instead, one must identify the activities and the way in which they are carried out, the equipment involved and the postures the workers must adopt, the body parts that are subjected to work and for how long, the necessary force etc.

For instance, for reinforcing a floor with concrete iron bars (Figure 1), the worker must carry them close to where they will be mounted, put them in place and then tie them together with wires.

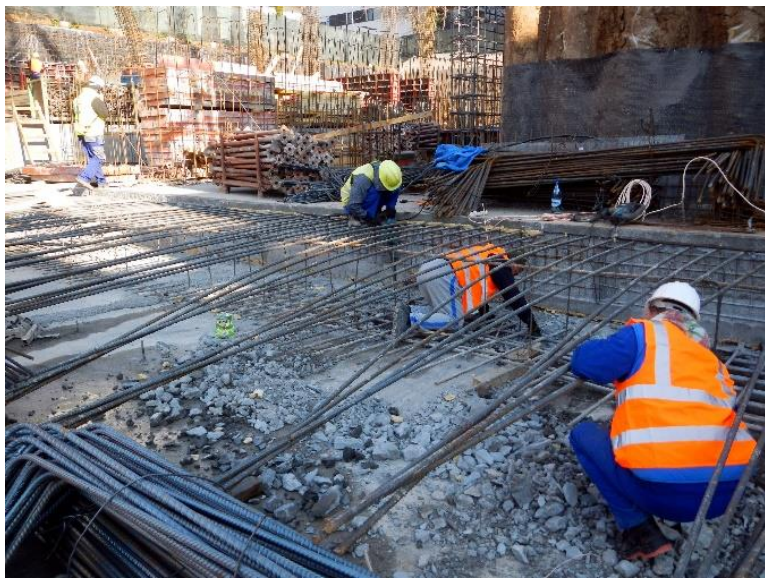

a. Placing concrete iron bars on site

Observed postures: squat, on knees

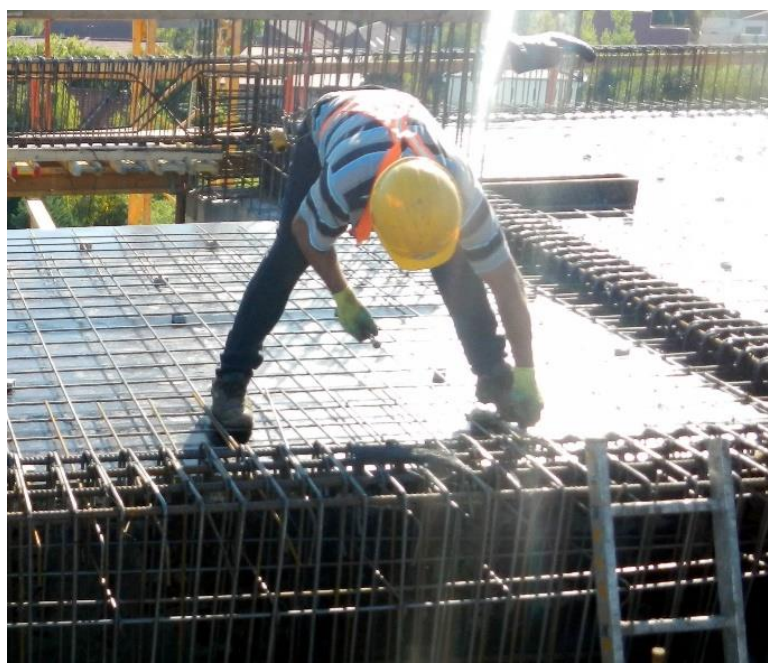

c. Armature binding

Observed postures: bent forwards at over $90^{\circ}$

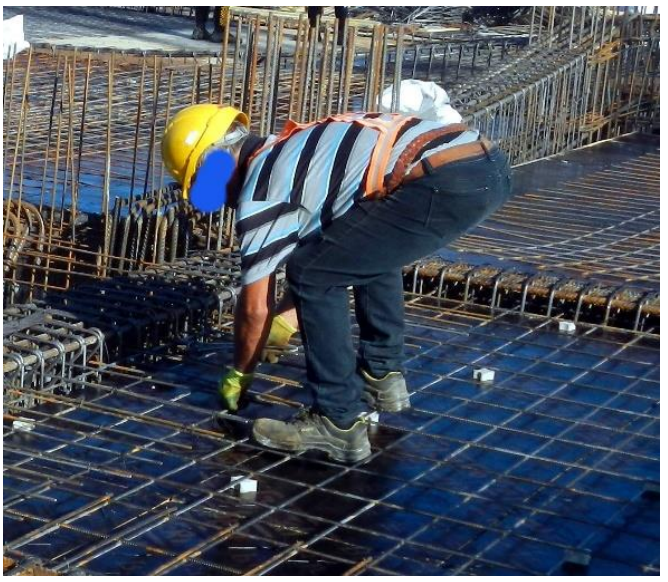

b. Armature binding

Observed postures: bent forwards, squat

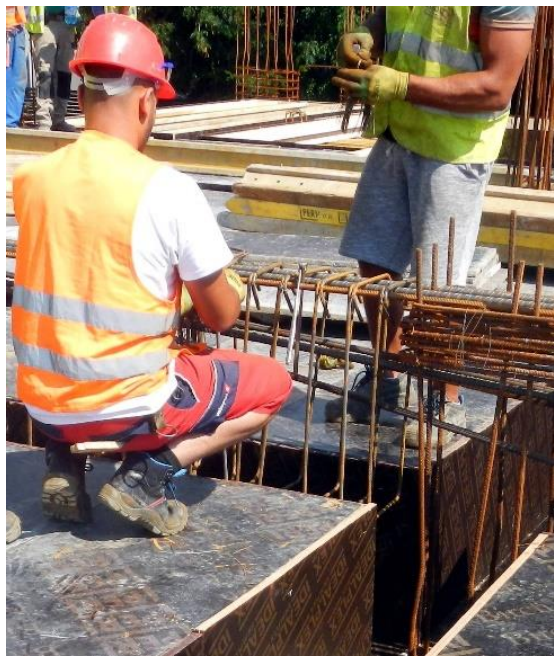

d. Armature binding

Observed postures: squatting, sitting on tiptoes Duration of holding the posture: $1-6$ min. Frequency: 5-15 times/hour Fig. 1. Work situations for the armature binding activity

\subsection{Parameters of QERA method}

QERA method is applied to every activities in a workplace and to every jobs that perform them. The method considers four important body parts that are physically involved in different activities: neck, torso, arms, and legs.

The following aspects are considered for each body part: 
- Neck: position (flexed or extended), bended, rotated;

- Torso: position (flexed or extended), bended, rotated;

- Arms: one hand raised, two hands raised, twisted wrist;

- Legs: lean on one leg, flexed knees, sit on knees.

Additionally, the following factors are included:

- The impact of the activities on the body or on a body part,

- The force required,

- The time and frequency the posture is maintained or the force is applied.

Thereby, the method uses a simple scale to evaluate how the body parts are affected, fact presented in Table 1.

Table 1. Grid for assessing the impact on different parts of the body: neck, torso, arms, legs

\begin{tabular}{|c|c|c|c|c|c|c|}
\hline \multirow[b]{2}{*}{$\begin{array}{l}\text { Impact } \\
\text { level }\end{array}$} & \multirow[b]{2}{*}{ Impact } & \multicolumn{4}{|c|}{ Labor conditions } & \multirow[b]{2}{*}{ Measures } \\
\hline & & Posture & $\begin{array}{l}\text { Duration/ } \\
\text { frequency }\end{array}$ & Force & Cumulative & \\
\hline 1 & Negligible & Neutral posture & Low & Small/ Medium & $3 / 3$ & $\begin{array}{l}\text { No additional } \\
\text { measures are } \\
\text { required }\end{array}$ \\
\hline \multirow{2}{*}{2} & \multirow{2}{*}{ Small } & Awkward & Low & Small/ Medium & $2 / 3$ & \multirow{4}{*}{$\begin{array}{l}\text { Improvement } \\
\text { measures could } \\
\text { be taken }\end{array}$} \\
\hline & & Awkward & Medium & Small/ Medium & $2 / 3$ & \\
\hline \multirow{2}{*}{3} & \multirow{2}{*}{ Medium } & Awkward & Medium & Medium & $2 / 3$ & \\
\hline & & Awkward & High & Medium & $2 / 3$ & \\
\hline \multirow{3}{*}{4} & \multirow{3}{*}{ High } & Awkward & High & High & $2 / 3$ & \multirow[t]{5}{*}{$\begin{array}{l}\text { Measures must } \\
\text { be taken }\end{array}$} \\
\hline & & Very awkward & Low & Small/ Medium & $2 / 3$ & \\
\hline & & Very awkward & Medium & Small & $2 / 3$ & \\
\hline \multirow{2}{*}{5} & \multirow{2}{*}{ Very high } & Very awkward & $\begin{array}{l}\text { Medium / } \\
\text { High }\end{array}$ & Medium & $3 / 3$ & \\
\hline & & Very awkward & $\begin{array}{c}\text { Medium / } \\
\text { High }\end{array}$ & Small/ High & $3 / 3$ & \\
\hline
\end{tabular}

Explanations (with examples) regarding the values in the Table 1:

Neutral posture - natural posture of the body or of the body parts. The body can be bent at maximum $20^{\circ}$.

Awkward posture - body bent between $20^{\circ}$ and $45^{\circ}$, body slightly inclined laterally or rotated, body leaned on one leg, knees flexed at maximum $30^{\circ}$, neck slightly flexed, bended or rotated.

Very awkward posture - body bent over $45^{\circ}$, body laterally bended or rotated, knees flexed over $30^{\circ}$, neck bent, bended or rotated, at least one knee touches the ground.

Duration/frequency - depends on how time is perceived when a worker keeps a certain posture or applies a certain force with a certain intensity. For example, if it takes a worker one minute to tie an armature at hip level, the duration is perceived as being low. On the other hand, if the worker ties it with the hands above the head, one minute is perceived as medium duration, while, if it takes over 5 minutes, the duration is perceived as high.

Force (applied) - depending on the worker's abilities and other factors like posture, the necessary force for carrying out a task is perceived differently. For example, a load weighing $10 \mathrm{~kg}$ might require a small force when applied in a normal posture, but a medium or even a high force might be needed if the body is inclined at over $60^{\circ}$.

Cumulative - the number of factors out of the total number of factors (3) that act simultaneously. For example, for the impact level of value 2, 2/3 means that 2 out of 3 factors (awkward posture and medium force) are enough to cause it. The three factors are: posture, duration/ frequency and force. 
RECENT, Vol. 21, no. 3(62), 2020

For each body part (neck, trunk, arms, legs), the impact level is determined from the grid.

In practice, there are other additional factors that influence the impact level, such as those presented in Table 2.

Table 2. Additional risk factors

\begin{tabular}{|c|c|c|c|}
\hline \multicolumn{2}{|c|}{ Additional factors } & + & Description \\
\hline \multirow{3}{*}{ Load weight } & Light & 1 & $<10 \mathrm{~kg}$ \\
\hline & Medium & 2 & $11 \mathrm{~kg} \leftrightarrow 20 \mathrm{~kg}$ \\
\hline & Heavy & 3 & $>20 \mathrm{~kg}$ \\
\hline \multirow{3}{*}{$\begin{array}{l}\text { Weather } \\
\text { conditions }\end{array}$} & Optimal & 1 & $15^{\circ} \mathrm{C} \leftrightarrow 25^{\circ} \mathrm{C}$, humidity approx. $50 \%$, air speed $<0.5 \mathrm{~m} / \mathrm{s}$ \\
\hline & Awkward & 2 & $\begin{array}{l}8{ }^{\circ} \mathrm{C} \leftrightarrow 15{ }^{\circ} \mathrm{C} / 25{ }^{\circ} \mathrm{C} \leftrightarrow 33{ }^{\circ} \mathrm{C} \text {, humidity } 25 \leftrightarrow 30 \% \mid 70 \\
\leftrightarrow 75 \% \text {, air speed } 0.5 \mathrm{~m} / \mathrm{s} \leftrightarrow 10 \mathrm{~m} / \mathrm{s}\end{array}$ \\
\hline & Very awkward & 3 & $<8{ }^{\circ} \mathrm{C} />33^{\circ} \mathrm{C} \mid$ humidity $<25 \% \mid>75$, air speed $>10 \mathrm{~m} / \mathrm{s}$ \\
\hline
\end{tabular}

The additional factors contribute with the value displayed in the ' + ' column, which is added to the value resulted from Table 1 . The additional factors are added, if appropriate, only to the values in the columns: trunk, arms, and legs, as seen in Table 3 . If the total is larger than 5 , then the final value is 5.

Table 3. Assessing the impact level on the body while perming various tasks

\begin{tabular}{clcccc}
\hline & \multicolumn{2}{c}{$\begin{array}{c}\text { Activity } \\
\text { Name }\end{array}$} & Neck & \multicolumn{2}{c}{ Affected body part } \\
Trunk & Arms & Legs \\
\hline 1 & Digging & 2 & 5 & 4 & 4 \\
2 & Armature binding & 4 & 5 & 2 & 4 \\
3 & Pouring concrete & 1 & 4 & 4 & 2 \\
4 & Masonry & 2 & 4 & 4 & 2 \\
5 & Tile, faience installation & 3 & 5 & 4 & 5 \\
6 & Mounting a scaffold & 2 & 4 & 4 & 2 \\
7 & Parquet installation & 3 & 5 & 3 & 4 \\
8 & Pavement, curb installation & 1 & 4 & 4 & 3 \\
9 & Sanitary installation & 3 & 4 & 4 & 4 \\
10 & Electrical wiring & 3 & 4 & 4 & 4 \\
11 & Welding & 3 & 4 & 4 & 4 \\
12 & Carpentry, woodworking & 4 & 5 & 4 & 4 \\
\hline
\end{tabular}

\section{Results}

After analyzing the results obtained by observing workers while carrying out activities and by interviewing them (through questionnaires as well), we could assess the impact levels on different parts of the body for a series of activities by applying QERA.

For certain activities some body parts, such as the arm wrists, are greatly stressed. For instance, tying rebar by hand increases the risk of developing hand-wrist disorders. This risk is due to the forces applied by the hand when gripping pliers and to the rapid hand movements when wrapping and twisting wires. These movements force the wrist and forearm to twist and causes a high pressure on the arm [7]. These issues must be considered when trying to determine the impact level on the arms.

Rebar is tied by hand with pliers and hand and arm movements while applying a lot of force. If rebar is tied at ground level, a stooped position must be adopted, with the body bent deeply forward.

Tying rebar by hand increases one's chance of developing hand-wrist disorders due to the high hand forces used to grip pliers, the rapid hand movements used to wrap and twist wire, and the high pressure on the hand. The assessment of the level of affectation of the body areas at the execution of the different activities according to the values shown in Table 1 are presented in Table 3.

Additionally, Figure 2 shows the graph of parts of the body impacted by these activities. The additional factors were not included. 


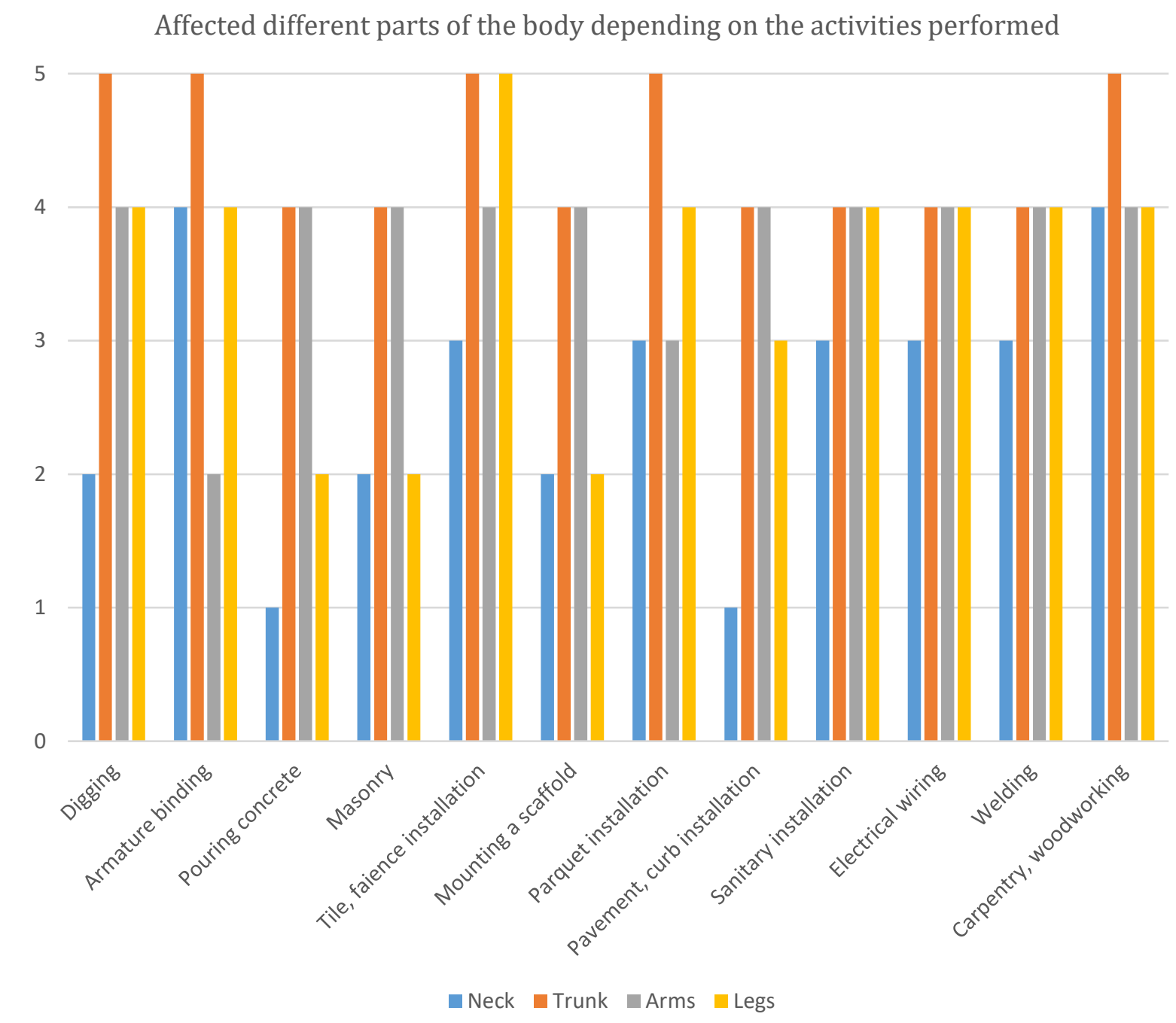

Fig. 2. Impact levels of different activities on the body

The activity tile installation requires the worker to bring the tiles to the work site (a pack could even weigh $24 \mathrm{~kg}$ ), prepare the adhesive, cut the tiles, place and fix the tiles on spot, grout, etc. Most of these actions are carried out at floor level such that the worker must bend over and / or sit on the knees. Likewise, to prevent moving the legs, the worker rotates or inclines his body in order to pick up the materials needed (e.g. tiles, adhesive, tools, etc.). Hence, this activity mostly affects the torso (vertebral column). The representation of the impact level of the body areas when performing different activities is presented in Figure 3.

For an easier understanding, Figure 3 is a visual representation of the parts of the body affected when executing different activities. The colors represent the impact level for each body part and are in accordance with those in Table 1.

After studying Figure 3 it can be concluded that:

- Tile installation has a high impact level on the worker's trunk and legs;

- Carpentry and digging ditches have a very high impact level on the trunk and a high impact level on the legs and arms;

- Parquet installation has a very high impact level on the trunk, a high level on the legs and a medium level on the arms.

To improve the accuracy of the assessment, the additional factors that could significantly alter the impact level on the worker's body should also be considered. Figure 4 shows a "simple solution" for manually tying iron bars. 
RECENT, Vol. 21, no. 3(62), 2020

Digging

Figure 3. Visual representation of the impact of different activities have on the body

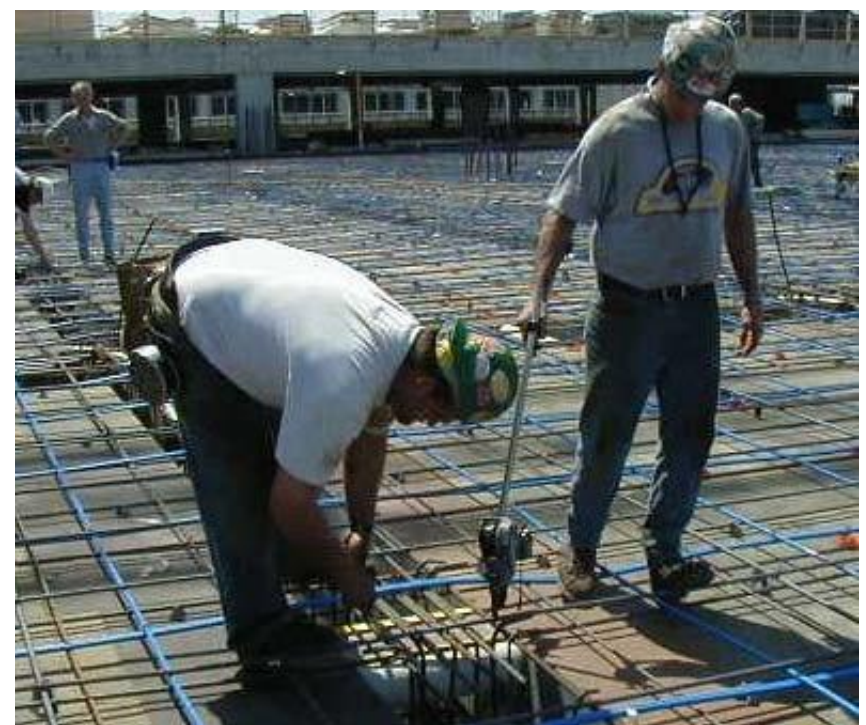

Fig. 4. Illustration of an 'easy' solution. Notice the difference in posture when the iron bars are tied manually and when they are tied using a machine [8]

According to this assessment, measures that prevent ergonomic risks are chosen. However, the technical measures and the measures regarding the workers' exposure to these risks are the most efficient and should be implemented first. The implemented measured ought to optimize the interactions between employees, work tasks, work equipment and work environment in order to improve safety, performance and usability (effectiveness, efficiency and satisfaction) [9].

\section{Conclusions}

All work situations have specific characteristics and should be analysed separately. The present study highlights the fact that many activities are carried out while ignoring the ergonomic risks which affect the health and security of the employees. At the same time, it was revealed that workers are not aware of and do not fully understand how these risks could impact them. The same is true for the employers who do not provide the employees with the proper technical means or efficient training.

The new assessment method for the impact level on different body parts - QERA - is easy and quick to apply, even prior to the start of the activities, such that measures can be implemented and the ergonomic risks can be minimized or eliminated. A significant advantage of this method in practice is the use of a visual diagram/ map of the affected body parts as well as their impact level by using color codes. 
Applying the method on different types of activities (it has also been applied prior to the current study) gave the expected results. This demonstrates its efficiency for this kind of ergonomic risks assessments, where the assessment must be completed in a short time and no stuff qualified in the health and safety field is required.

Assessing the ergonomic risks is very important for creating safe working conditions. It is informative, motivational and it decreases the number of accidents and musculoskeletal ailments. Similarly, it decreases the number of sick days, the fluctuations in personnel, the hospitalization costs etc. Moreover, the assessment depicts the current situation in the civil construction field and motivates positive change. Improving ergonomic performances of activities in the construction fields is performed after the ergonomic risk assessment, considering the technical progress of equipment and work methods, such that the employees are exposed to these risks to the least extent. It is also performed by eliminating or reducing awkward positions. Further research is therefore fully justified and necessary.

\section{References}

1. Cieslewicz W., Araszkiewicz K., Sikora P. (2019): Accident Rate as a Measure of Safety Assessment in Polish Civil Engineering. Safety, ISSN 2313-576X, Vol. 5, no. 4, https://doi.org/10.3390/safety5040077

2. European Agency for Safety and Health at Work (2019): Work-related musculoskeletal disorders: prevalence, costs and demographics in the EU. Publications Office of the European Union, ISBN 978-92-9479-145-0, doi:10.2802/66947

3. ***: What is Ergonomics? IEA - International Ergonomics Association, https://iea.cc/what-is-ergonomics/

4. ${ }^{* * *}$ (2017): Guidelines on Ergonomics Risk Assessment at Workplace. Department of Occupational Safety and Health, Ministry of Human Resources, Malaysia, Putrajaya, p. 4, https://www.dosh.gov.my/index.php/ competent-person-form/occupational-health/regulation/guidelines/ergonomic/2621-01-guidelines-onergonomics-risk-assessment-at-workplace-2017/file

5. *** (2015): Ergonomics Good Practice in the Irish Workplace. Authority Health and Safety, Dublin, p. 11, https://www.hsa.ie/eng/Publications and Forms/Publications/Manual_Handling and_Musculoskeletal_Dis orders/Ergonomics Good Practice.pdf

6. Szabó G. (2017): Assessment methods of ergonomic risks. EASOM Summer School, p. 7, https://www.easom.eu/ images/pdf/summerschools/summerschool17/Gyula Szabo-Assessment methods ergonomic risks.pdf

7. Albers J.T., Estill C.F. (2007): Simple Solutions - Ergonomics for Construction Workers. U.S. Department of Health and Human Services, National Institute for Occupational Safety and Health, Cincinnati, USA, p. 27, https://www.cdc.gov/niosh/docs/2007-122/pdfs/2007-122.pdf?id=10.26616/NIOSHPUB2007122

8. Almeida T., Vi P. (2004): Reducing Risk of Musculoskeletal Disorders and Promoting - Return-To-Work Through The Use Of Rebar Tying Machines. Rodworkers Intervention Studies, WSIB Grant \#01023, Final Report, Etobicoke, Ontario, Canada, p. 14, http://citeseerx.ist.psu.edu/viewdoc/download; jsessionid=2DAD681FF84C5FF1A16EBDB15E1ED985?doi=10.1.1.620.4853\&rep=rep1\&type=pdf

9. ISO 26800:2011 (2011): Ergonomics - general approach, principles and concepts. Geneva, Switzerland, https://www.iso.org/standard/42885.html 